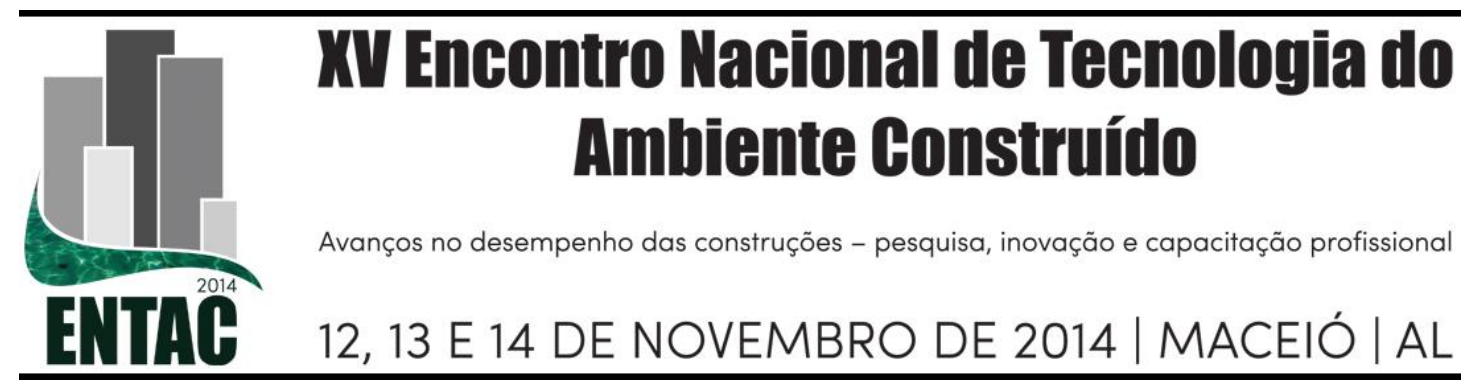

\title{
PROPOSTA DE IMPLANTAÇÃO DE UM PROGRAMA DE USO RACIONAL DE ÁGUA NO EDIFÍCIO DAS FACULDADES DE FARMÁCIA E ODONTOLOGIA
}

\author{
PACHECO, Gabriela Ribeiro (1); CAMPOS, Natália Cristina (2); CAMPOS, \\ Marcus André Siqueira (3) \\ (1) Universidade Federal de Goiás, gabi_ribeiro@hotmail.com (2) Universidade Federal de Goiás, \\ natcampos91@hotmail.com, (3) Universidade Federal de Goiás, marcusscampos@gmail.com
}

\begin{abstract}
RESUMO
Visto que a água é um recurso indispensável à sobrevivência humana, há uma crescente preocupação com a criação de soluções para reduzir o seu consumo, desde o abastecimento até o usuário final. Este trabalho contempla o processo de implantação de um Programa de Conservação de Água em um edifício de um Câmpus Universitário. Considerando a existência de inúmeras tipologias de uso, que abrangem desde clínicas a salas de aula, é realizado um diagnóstico do estado de conservação, das condições de operação das instalações hidrossanitárias, e assim, são definidas ações para reduzir o consumo. Desta forma, para o edifício das Faculdades de Odontologia e Farmácia da Universidade Federal de Goiás estima-se um volume de perdas que totalizam 2166 litros por dia. É estabelecido um plano de intervenções que propõe inicialmente ações para a correção de vazamentos. A partir daí, recomenda-se a substituição dos aparelhos convencionais por economizadores e o aproveitamento de fontes alternativas. Para que a redução no consumo seja permanente é necessário ainda realizar manutenções preventivas periodicamente.

Palavras-chave: Programa de Conservação de Água. Programa de Uso Racional de Água. Sistemas prediais. Equipamentos sanitários. Patologias e vazamentos.

ABSTRACT

Once water is an essential resource for human survival, there is a growing concern about the creation of solutions to reduce its consumption, from the supply to the end users. Therefore, this work describes the process of implementing a Water Conservation Program in a building of a University Campus. Given the several types of uses, ranging from clinics to classrooms, a diagnosis of the conservation state and the operating conditions of plumbing facilities, is carried out. After that actions to reduce consumption are defined. In this way, for the building of the School of Dentistry and Pharmacy of the Federal University of Goiás (Universidade Federal de Goiás) it is estimated a volume of water losses totaling 2166 litres per day. It is established a plan of interventions that initially proposes actions to fixing leaks. From that, it is recommended the replacement of conventional equipments by water saving devices and the use of alternative sources. For consumption reduction be permanent, it is still necessary to accomplish preventive maintenance periodically.
\end{abstract}

Keywords: Program of Water Conservation. Program of Rational Use of Water. Building Systems. Sanitary appliances. Pathologies and leaks.

\section{INTRODUÇÃ̃O}

A água é um recurso abundante no planeta, no entanto, de acordo com Clarke e King (2005), 97,5\% de seu total é salgado e $69,5 \%$ do restante está indisponível nas geleiras. 
O Brasil, segundo estes mesmos autores, detém $12 \%$ do volume total de água doce, contudo, sofre com o problema da má distribuição dos mananciais e também com a baixa qualidade dos mesmos. Esta última causada pela ação humana que gera crescentes níveis de poluição. O crescimento populacional constante e a intensificação das atividades econômicas contribuem para o aumento da demanda, agravando ainda mais o problema da escassez.

Atualmente, no país, o aproveitamento de águas pluviais não é muito difundido, o reuso é pouco praticado e a água contaminada é tratada de forma inadequada. Assim o custo de tratamento eleva-se e o gerenciamento da mesma torna-se muito mais complexo. Desta forma percebe-se a importância da gestão dos recursos disponíveis, tornando essencial a implantação de uma política de conservação.

Sautchúck (2004) aponta que, de um modo geral, o processo de conservação deste recurso se inicia com a otimização do consumo, de forma a minimizá-lo, como é inicialmente proposto por um Programa de Uso Racional de Água (PURA). Feito isso, devem ser analisadas as fontes alternativas de água, como estabelece um Programa de Conservação de Água (PCA). Compreendendo ações que resultem na economia deste recurso, atuando de maneira sistêmica sobre a oferta e demanda do mesmo, conforme define Sautchuk et al. (2006).

A utilização da água deve ser analisada desde o nível macro, que abrange o gerenciamento dos recursos hídricos em bacias hidrográficas, até o nível micro, representado pelos sistemas prediais. Vale ressaltar que os programas de uso racional aplicados neste nível têm sido amplamente utilizados nos últimos anos, principalmente para as edificações institucionais, industriais e comerciais. Isso se deve ao fato da abordagem mais próxima do usuário final ser mais eficiente no que diz respeito à facilidade de intervenção e a obtenção de resultados. Dentre eles destacam-se o Programa de Uso Racional de Água da Universidade de São Paulo (PURA-USP), apresentado por Nunes (2000), o Programa de Conservação de Água da Universidade Estadual de Campinas (PRÓ-ÁGUA), detalhado por Silva (2004), e o estudo de Gomes (2011) realizado na Universidade Federal de Goiás.

O presente trabalho, tem o intuito de estabelecer ações para implantação de um Programa de Conservação de Água (PCA) em um edifício da Universidade Federal de Goiás usando a metodologia do PURA desenvolvido pela Universidade de São Paulo.

\section{METODOLOGIA}

Primeiramente foi escolhida a edificação de estudo. Em seguida a população fixa foi quantificada através de informações obtidas junto às coordenações de cada unidade, que forneceram o número de alunos matriculados, bem como de professores e funcionários cadastrados. A estimativa da população flutuante, representada pelos usuários dos laboratórios e clínicas, foi realizada a partir de uma média do número de atendimentos realizados no prédio.

Para estimar o consumo de água foi feito um levantamento do mesmo através das faturas de cobrança da Companhia de Saneamento Local. Dessa forma determinou-se o índice de consumo (IC), que é a relação entre a quantidade total de água consumida e o número de usuários.

Foram levantados os projetos arquitetônicos e hidrossanitários da edificação em questão, e assim, identificados os pontos de consumo de água, sendo as atualizações observadas após uma verificação em campo. 
Foi realizado o cadastramento dos aparelhos instalados em cada ponto de consumo. Para tanto, foi necessário examinar o estado de conservação dos mesmos. Além disso, foi verificada a existência de vazamentos, a partir do exame visual, e identificada a forma dos mesmos. Calculou-se o índice de vazamentos (IV), que é a relação entre o número de pontos de utilização com esta manifestação patológica e o total. Finalmente, foi estimado o volume perdido através dos vazamentos e calculado o índice de perdas (IP), que é a relação entre o volume de perdas visíveis e invisíveis e o consumo médio diário.

Com base nas informações obtidas na pesquisa, foram identificados os pontos críticos que contribuem para o aumento do consumo de água. Assim, estabeleceu-se as ações mais eficazes para cada tipo de problema, tais como conscientização dos usuários e substituição de aparelhos comuns por economizadores.

\section{RESULTADOS}

O edifício que abriga as Faculdades de Farmácia e Odontologia da Universidade Federal de Goiás foi selecionado por seu grande potencial de redução de consumo de água e por apresentar necessidade de reabilitação profunda, como aponta Oliveira (2013). Isso torna indispensável realizar uma investigação das manifestações patológicas do Sistema Predial Hidrossanitário para preservar a edificação e também torná-la sustentável. Desta forma, a partir de um diagnóstico das condições do mesmo e de suas instalações hidrossanitárias foram sugeridas medidas para reduzir o consumo.

\subsection{LEVANTAMENTO DA CONSUMO DE ÁGUA DO EDIFÍCIO}

A edificação foi construída em 1989 e apresenta uma área construída de $7932 \mathrm{~m}^{2}$. Conta com salas de aula, gabinetes, secretarias, laboratórios, banheiros, copas, um auditório e uma cantina. Além disso tem-se o Laboratório Rômulo Rocha (que presta serviços de análises clínicas), a Farmácia-Escola, quatro ambulatórios odontológicos (onde os alunos realizam consultas gratuitamente) e o Centro Goiano de Doenças de Boca (CGDB) que oferece tratamento para pacientes com lesões bucais. A existência de inúmeras tipologias resulta em uma investigação bastante complexa, já que possuem necessidades distintas.

A circulação de pessoas no edifício em questão é intensa. O número de professores, alunos e funcionários das unidades foi obtido nas coordenações de cada curso. Os atendentes do Laboratório Rômulo Rocha e do Serviço de Atendimento ao Público (SEAP) da Faculdade de Odontologia estimaram uma média dos atendimentos realizados por dia neste laboratório e nos ambulatórios. Na Faculdade de Farmácia são 37 professores e 376 alunos e 51 funcionários, tendo 60 atendimentos diários. Já na Faculdade de Odontologia são 60 professores, 298 alunos e 40 funcionários, tendo 55 atendimentos diários. As duas unidades compartilham 5 funcionários para a segurança e 10 de limpeza. Assim, chegou-se nos valores 877 e 115, correspondentes às populações fixa e flutuante do edifício.

Verificou-se o consumo de água com base nas faturas de cobrança da SANEAGO, disponibilizadas pelo Centro de Gestão do Espaço Físico (CEGEF). O edifício conta com apenas um hidrômetro, logo as duas unidades foram analisadas conjuntamente. Foram levantados os preços das faturas de março de 2011 a setembro de 2013. O consumo médio foi calculado a partir dos dados situados no intervalo entre a média inicial e uma variação de mais e menos o desvio padrão e equivale a $602,62 \mathrm{~m}^{3} / \mathrm{mês}$ ou $20,09 \mathrm{~m}^{3} /$ dia. Os valores das contas para o mesmo período, de março de 2011 a setembro de 2013, variaram de $\mathrm{R} \$ 3.216,77$ até $\mathrm{R} \$ 14.148,99$. 


\subsection{LEVANTAMENTO PATOLÓGICO E ESTIMATIVAS DE PERDAS}

Não foram analisadas partes da edificação que não estavam sendo utilizadas durante o período da coleta ou passavam por reforma. As 98 cadeiras odontológicas existentes nos ambulatórios da Faculdade de Odontologia não foram incluídas no estudo. Foi feita apenas uma análise global das mesmas, que em geral, apresentavam-se em bom estado de conservação. Poucos registros foram averiguados devido à altura dos mesmos, mas pode-se estimar a quantidade de patologias e o estado geral considerando esta amostra.

Foi verificada a existência de 308 aparelhos, conforme apresentado na Tabela 1. De uma forma geral, os equipamentos sanitários apresentaram estado de conservação adequado. No entanto, muitos estão corroídos, sujos e com vazamentos. Além disso, foram observadas várias improvisações que ocorrem devido à idade das instalações, que não mais conseguem atender às necessidades dos usuários.

Tabela 1 - Diagnóstico dos aparelhos

\begin{tabular}{|c|c|c|c|c|c|c|}
\hline \multirow[b]{2}{*}{ Aparelhos } & \multirow[b]{2}{*}{ Total } & \multirow{2}{*}{$\begin{array}{c}\text { Aparelhos } \\
\text { sem } \\
\text { patologias }\end{array}$} & \multicolumn{4}{|c|}{ Aparelhos com patologias } \\
\hline & & & Vazamento & $\begin{array}{l}\text { Fixamento } \\
\text { inadequado }\end{array}$ & Entupimento & Outros \\
\hline Bacias Sanitárias & 42 & 34 & 5 & 1 & 1 & 1 \\
\hline Bebedouros Elétricos & 8 & 5 & 0 & 0 & 0 & 3 \\
\hline Chuveiros & 5 & 1 & 0 & 0 & 0 & 4 \\
\hline Duchas Higiênicas & 3 & 0 & 1 & 0 & 0 & 2 \\
\hline $\begin{array}{l}\text { Equipamentos de } \\
\text { Uso Específico }\end{array}$ & 14 & 14 & 0 & 0 & 0 & 0 \\
\hline Lavatórios & 32 & 30 & 1 & 1 & 0 & 0 \\
\hline Lavatórios tipo Calha & 2 & 2 & 0 & 0 & 0 & 0 \\
\hline Mictórios & 7 & 3 & 4 & 0 & 0 & 0 \\
\hline Pia & 6 & 4 & 1 & 0 & 0 & 1 \\
\hline Registros & 7 & 5 & 1 & 1 & 0 & 0 \\
\hline Tanques & 6 & 3 & 1 & 1 & 1 & 0 \\
\hline Torneiras com filtro & 1 & 1 & 0 & 0 & 0 & 0 \\
\hline Torneiras de lavagem & 100 & 77 & 4 & 11 & 4 & 4 \\
\hline Tor. economizadoras & 75 & 59 & 9 & 5 & 0 & 2 \\
\hline \multirow{2}{*}{ TOTAL } & 308 & 238 & 27 & 20 & 6 & 17 \\
\hline & & $77,27 \%$ & $8,77 \%$ & $6,49 \%$ & $1,95 \%$ & $5,52 \%$ \\
\hline
\end{tabular}

Fonte: Elaborado pelo autor.

As bacias sanitárias, todas com válvula de descarga, exibiam um estado de conservação satisfatório. A principal patologia verificada nestes elementos foi a ocorrência de vazamentos nas válvulas de descarga.

As torneiras de lavagem foram o equipamento mais expressivo em termos de quantidade. As patologias apresentadas nestes aparelhos sanitários incluem má fixação, entupimentos e vazamentos, tanto nas torneiras e registros, como nos sifões. Algumas destas são causadas pelo próprio uso a que se destinam, como a torneira do laboratório 
de prótese que entope frequentemente devido ao uso de gesso, mesmo com tentativas de separar tal material antes do descarte na rede de esgoto. Percebeu-se que praticamente nenhuma torneira de lavagem possui arejador, e tais dispositivos são uma forma de reduzir o consumo de água.

Nos laboratórios da Faculdade de Farmácia existem várias torneiras de metal nas bancadas que não são utilizadas há muito tempo. Estas foram desconsideradas nesta pesquisa, que abrangeu apenas aquelas que ainda são pontos de consumo de água e já foram substituídas por torneiras de plástico. Nota-se uma tendência de substituição de elementos como torneiras, sifões e flexíveis de metal por PVC. Estes são normalmente mais baratos, mas podem apresentar problemas com um tempo menor de utilização.

Depois das torneiras de lavagem, as economizadoras foram as mais vistas, totalizando 75 unidades. Do total, 42 eram hidromecânicas, encontradas principalmente nos banheiros. Nos laboratórios e ambulatórios, encontrou-se 30 torneiras de sensor, e outras três com acionamento de pé. Verificou-se que muitas torneiras hidromecânicas não funcionam adequadamente, visto que há uma grande variação na duração do fluxo de água após seu acionamento. Algumas ficam abertas por um segundo enquanto outras permanecem por oito e o volume de água varia de 50 até $1000 \mathrm{ml}$.

As torneiras com sensor de presença frequentemente param de funcionar pois este dispositivo e sua bateria estragam facilmente. Esses defeitos costumam ocorrer devido ao contato com a água e para que eles não persistam, no Laboratório Rômulo Rocha estas foram protegidos com EVA. Isso evitou mais transtornos, no entanto, os ambulatórios da Faculdade de Odontologia contam com menos da metade dos seus lavatórios, já que sempre existem baterias e sensores danificados.

Os equipamentos de uso específico encontrados compreendem destiladores, tanques de revelação, duchas e lava olhos. Os tanques são usados para a revelação radiológica e atualmente estão sendo substituídos por impressoras que realizam esse processo automaticamente, restando apenas dois. A água usada nos mesmos é descartada diretamente para a rede de esgoto.

Encontrou-se um total de cinco duchas e lava olhos, tais equipamentos são usados somente em casos de emergência. Não foi possível verificar o funcionamento dos mesmos pois apresentam uma vazão elevada e, em alguns dos corredores onde estão instalados, não existem ralos próximos para escoamento da água.

Os destiladores realizam a vaporização e em seguida a liquefação, a fim de reduzir a quantidade de impurezas nos líquidos para fins laboratoriais. Foram encontrados quatro deles no edifício, os funcionários dos laboratórios estimaram o total de água destilada obtida em cada um. Os três aparelhos presentes na Faculdade de Farmácia produziam 300 litros de água destilada por dia e o volume descartado era coletado e usado em duas torneiras situadas no jardim em frente ao edifício. Enquanto na Faculdade de Odontologia o único destilador, situado no laboratório de patologia, produzia cerca de 15 litros de água destilada por dia e o volume perdido não era reaproveitado.

Nos equipamentos sanitários levantados nesta pesquisa foram examinadas patologias como vazamentos, entupimentos, fixação inadequada, partes danificadas ou retiradas, entre outras. Constatou-se que 70 aparelhos, $22,73 \%$ do total, apresentaram ao menos alguma das formas citadas.

Os vazamentos foram a manifestação patológica mais frequente, para a quantificação dos mesmos desconsiderou-se aqueles ocorridos em sifões e flexíveis, já que não geram aumento do consumo de água por pertencerem às instalações de esgoto. Foi observado 
que $8,77 \%$ dos equipamentos sanitários operam com alguma forma de vazamento, estes ocorrem nas torneiras, válvulas de descarga e registros.

Tal valor é bem menor que o encontrado no PRÓ-ÁGUA, segundo Nunes (2000) 18,6\% de 441 pontos apresentaram esta patologia. Nesse estudo realizado na UNICAMP as bacias com válvula de descarga e os mictórios obtiveram os índices mais elevados. Nas Faculdades de Farmácia e Odontologia os mictórios alcançaram o maior índice de vazamentos. Contudo, não foram realizados testes como o do corante e o da caneta, que provavelmente identificariam um número de vazamentos maior do que foi verificado apenas com o exame visual.

O volume de água perdido foi estimado depois de quantificados os vazamentos em cada tipo de aparelho e definido se estes ocorrem na forma de gotejamento lento, filete visível ou no registro. Assim, de acordo com o modelo de Sautchuk et al. (2006), tem-se uma perda de água diária de 1416 L.

Silva (2004) estimou a perda no processo de destilação a partir da análise de 240 aparelhos (a maioria do tipo Pilsen), chegando em um valor médio de $50 \mathrm{~L}$ de água de refrigeração perdida para cada litro do recurso destilado. Desta forma, no Laboratório de Patologia, que possui um destilador Pilsen, perde-se aproximadamente $750 \mathrm{~L} / \mathrm{dia}$. Considerou-se apenas $15 \mathrm{~L}$ de água destilada fabricada diariamente, já que o volume teoricamente desperdiçado nos destiladores da Faculdade de Farmácia já é reaproveitado. Totalizando, então, uma perda de $2166 \mathrm{~L} /$ dia no edifício, proveniente dos vazamentos e do destilador.

Durante o levantamento observou-se também a marca dos equipamentos, encontrou-se uma diversidade de fabricantes até para um mesmo tipo de aparelho. A fim de averiguar a qualidade das empresas em questão, fez-se uma análise da qualificação das mesmas através de um banco de dados disponibilizado pelo Governo Federal, através dos Programas Setoriais da Qualidade (PSQs), que fazem parte do Programa Brasileiro de Qualidade e Produtividade do Habitat (PBQP-H) (MINISTÉRIO DAS CIDADES, 2013). A análise foi feita com base na atualização valida até novembro de 2013.

Foi verificado um número expressivo de fabricantes que não possuem o certificado PBQP-H. Por se tratar de um edifício construído há mais de 20 anos, existe a possibilidade que as marcas não sejam comercializadas atualmente. Em contrapartida, pode ser que não houve a preocupação em adquirir produtos certificados.

\subsection{CÁLCULO DOS ÍNDICES}

Inicialmente foi calculado o índice de consumo (IC), que é a relação do volume de água consumida e o indicador de consumo. Apesar dos alunos, professores e funcionários terem sido considerados como população fixa sua presença no edifício varia muito de acordo com os turnos de serviço, horários de aula e atendimentos. Assim, tem-se como mais expressivo o uso deste recurso nos laboratórios e ambulatórios que atendem pessoas de fora da faculdade. Logo, definiu-se o número de atendimentos como indicador.

Considerou-se o consumo médio obtido a partir dos valores das contas de água disponibilizadas pelo CEGEF. Definindo um mês com 20 dias úteis. O IC foi determinado igual a 262 litros/atendimento/dia. Já o índice de vazamentos (IV), relação entre o número de pontos de utilização com esta patologia e o total, foi igual a $8,77 \%$ e o índice de perdas, através da divisão do volume de perdas visíveis pelo consumo médio diário foi igual a $7.19 \%$. Vale destacar que, durante o levantamento do estado das 
instalações hidrossanitárias, não se detectou as perdas por vazamento não-visível, no entanto estas possivelmente ocorrem uma vez que a maioria das tubulações e equipamentos são antigos

Com o intuito de compreender o que tais valores representam, os mesmos foram comparados com os índices calculados por Oliveira (1999) na implantação de dois PURAs: um no Instituto do Coração do Complexo do Hospital das Clínicas (InCor) e outro na Escola Estadual de Primeiro e Segundo Graus Fernão Dias Paes, todos indicados na Tabela 2.

Tabela 2 - Comparação de índices

\begin{tabular}{lccc}
\cline { 2 - 4 } & Farmácia e Odontologia & InCor $^{\mathbf{1}}$ & EEPSG $^{\mathbf{1}}$ \\
\hline Agentes consumidores & 115 atendimentos/dia & 314 leitos & 2445 alunos \\
\hline Consumo diário & $30,13 \mathrm{~m}^{3}$ & $509 \mathrm{~m}^{3}$ & $135 \mathrm{~m}^{3}$ \\
\hline IC & $262,01 \mathrm{~L} /$ atendimento/dia & $1618 \mathrm{~L} /$ leito/dia & $81,1 \mathrm{~L} /$ aluno/dia \\
\hline IV & $8,77 \%$ & $24 \%$ & $2,4 \%$ \\
\hline IP & $7,19 \%$ & $2,5 \%$ & $1,6 \%$ \\
\hline
\end{tabular}

${ }^{1}$ Oliveira (1999)

Fonte: Elaborado pelo autor

Embora esses edifícios não apresentem as mesmas características, ambos se aproximam de tipologias existentes nas Faculdades de Farmácia e Odontologia. Contudo, percebese que o consumo diário deste é bem menor. Já o índice de consumo e de vazamentos visíveis é intermediário. O índice de perdas por vazamentos foi maior que os outros dois, demonstrando que perde-se um grande volume de água através dos vazamentos identificados.

\subsection{ESTABELECIMENTO DE AÇÕES}

A partir do diagnóstico das instalações hidrossanitárias foram identificados os principais fatores que causam o aumento do consumo de água, e então, definidas medidas para conter tal crescimento. Recomenda-se que um plano de intervenção se inicie por seu ponto crítico, ou seja, os vazamentos detectados. Primeiramente, deve ser feita a manutenção e correção no sistema hidráulico externo, impedindo perdas de água e verificando a pressão. Só então são realizadas intervenções no sistema interno.

No edifício das Faculdades de Farmácia e Odontologia, as condições de conservação e operação dos sistemas prediais de água fria, esgoto e equipamento sanitário indicaram necessidade de manutenção. Neste caso específico, é necessário controlar os vazamentos, principalmente nas bacias, mictórios, torneiras economizadoras e de lavagem. Nas bacias sanitárias, deve-se consertar principalmente as válvulas de descarga que apresentaram vazamento considerável nas paredes quando acionadas.

As torneiras de lavagem apresentaram vazamentos através da bica e do registro de pressão. Provavelmente, os reparos ou anéis de vedação serão substituídos. Também é fundamental consertar problemas no sifão, ainda que estes não representem aumento no consumo de água.

As torneiras hidromecânicas manifestaram vazamentos no botão acionador e mostraram-se desreguladas. O tempo de abertura das mesmas deve variar de 6 a 12 segundos, de acordo com Sautchuk et al. (2006). Verificou-se uma média de cinco 
segundos nas torneiras vistoriadas, com alguns períodos de escoamento muito curtos, chegando a um segundo. Intervalos como estes obrigam o usuário a acionar o botão várias vezes causando desconforto e aumento do consumo de água.

Muitas também apresentaram vazão elevada. Logo devem ser realizadas intervenções como troca de pistão, ajuste do registro regulador e substituição do anel de vedação ou do reparo. Tais problemas foram identificados da mesma forma em mictórios e devem ser adotados os mesmos procedimentos.

Estas intervenções também devem ser executadas em pias, tanques, lavatórios, registros e qualquer equipamento que apresente algum tipo de vazamento. Patologias como entupimentos e fixação inadequada não acarretam aumento no consumo de água, entretanto, devem ser corrigidas.

Só após a realização dessas medidas indica-se substituir os equipamentos convencionais por economizadores. Caso contrário, isto pode mascarar resultados, principalmente se os vazamentos ocorrerem no sistema hidráulico externo. Portanto, esta ação deve ser implantada somente em instalações que apresentem um desempenho ideal. Sua meta é reduzir o consumo independentemente da colaboração dos usuários.

Com base na análise das atividades desenvolvidas, da forma de instalação, da possibilidade de manutenção e conforto do usuário, assim como da viabilidade econômica, indica-se para o edifício em estudo, a utilização dos seguintes equipamentos economizadores: bacias sanitárias com volume de descarga reduzido, torneiras com válvulas de pé, arejadores e restritores de vazão.

As bacias mais antigas consomem até 12 litros de água por descarga e hoje as que contam com volume de descarga reduzido funcionam com apenas seis. Desta forma, se o uso das mesmas for impraticável, deve-se optar pelos modelos de caixa acoplada que gastam um volume fixo de aproximadamente seis litros. Ou então, pode-se recorrer às válvulas de descarga com duplo acionamento, um para resíduos líquidos (vazão de 3 litros) e outro para sólidos (com 6 litros).

Recomenda-se o uso de torneiras acionadas através de válvulas de pé, já que os equipamentos com sensores de presença ficam frequentemente inoperantes esperando por conserto. Como mostrou-se eficiente a proteção das baterias e sensores, este procedimento deve ser executado em todos os equipamentos existentes, a fim de evitar novos problemas com estes equipamentos. A equipe de manutenção da universidade não consegue atender a todos as ordens de serviço imediatamente. Além disso, o custo deste tipo de reparo é alto, dado que na maioria das vezes é necessário comprar novas baterias e até sensores.

Os arejadores são dispositivos inseridos nas bicas das torneiras que limitam a vazão de escoamento, além de regular a dispersão do jato de água, promovendo uma redução no consumo. Sua instalação só não é aconselhada em tanques, torneiras de jardins e nas destinadas à limpeza, visto que as vazões elevadas são indispensáveis para seu desempenho adequado.

Juntamente com a substituição dos aparelhos convencionais, deve-se buscar $\mathrm{o}$ reaproveitamento da água de sistemas especiais. Neste edifício perde-se um grande volume no processo de destilação. A Faculdade de Farmácia já reaproveita esse recurso, no entanto, a Odontologia deve estabelecer um sistema semelhante. Uma vez que o destilador do Laboratório de Patologia encontra-se na parede da fachada, a água desperdiçada seria facilmente levada até o jardim, onde estão as torneiras alimentadas 
pelos outros destiladores. Além disso, é necessário estruturar um mecanismo para resfriar e reservar a água.

De acordo com Silva (2004), uma solução mais eficiente que o reaproveitamento é a substituição gradual dos equipamentos atualmente usados por outros mais sofisticados. Estes apresentam uma perda menor, e até nula como, por exemplo aqueles que executam a troca iônica, osmose reversa, ultrafiltração e radiação ultravioleta.

Outra alternativa seria centralizar a produção de água destilada, o que demandaria um menor investimento em equipamentos, mesmo que fossem usados os destiladores convencionais e realizado o reaproveitamento. Esta central deve ser considerada especialmente devido à intenção da Faculdade de Odontologia em produzir água destilada para uso em seus ambulatórios, já que hoje utiliza-se apenas a filtrada.

Em um Programa de Conservação de Água deve-se realizar campanhas educativas durante todo o processo, a fim de diminuir a demanda por esse recurso. A divulgação tanto do diagnóstico como do plano de intervenção já é uma forma de envolver os usuários e conscientizá-los. Dessa forma, cria-se o interesse na redução do consumo e no uso de fontes alternativas, como o reuso da água proveniente dos destiladores.

Deve-se orientar o pessoal da manutenção, limpeza, administração e usuários sobre o uso racional da água e como cada um pode colaborar. É fundamental oferecer treinamentos para o conserto adequado de vazamentos, orientações para manutenção preventiva, procedimentos compatíveis com cada manifestação patológica e também estabelecer uma programação dos serviços.

Os funcionários administrativos precisam se atentar às informações da concessionária, do pessoal da manutenção e dos usuários. No caso de consumo excessivo, por exemplo, devem tentar detectar a causa do problema para solucioná-lo.

É importante criar parâmetros de qualidade a fím de orientar a compra de novos aparelhos sanitários. Estes tem que contemplar normas técnicas e programas de qualidade. Um requisito bem simples é a adequação do produto com o Programa Setorial da Qualidade (PSQ). Além disso, é indispensável verificar os dispositivos com baixo consumo de água.

Para que a redução no consumo seja permanente, é necessário realizar manutenções preventivas no sistema hidráulico periodicamente, identificando e impedindo a ocorrência de vazamentos. Uma maneira de obter um maior controle dos desperdícios e vazamentos é a implantação de um sistema de medição setorizada do consumo. Dessa forma, seriam prontamente identificados os locais onde ocorrem consumos excessivos, podendo ser feitas as intervenções imediatas.

\section{CONSIDERAÇÕES FINAIS}

De acordo com os dados apresentados conclui-se que o levantamento realizado nesse trabalho é de suma importância para se ter o diagnóstico de um sistema de distribuição de água fria. A partir dele, aponta-se as principais deficiências, bem como a necessidade de manutenção ou substituição de aparelhos, que no trabalho em questão, são informações bastante válidas para o Centro de Gestão do Espaço Físico da Universidade. Dessa forma, é possível propor soluções para aumentar a eficiência do sistema predial de água, a fim de tornar mais viável a implantação de programas que visem ao uso racional e conservação deste recurso. 
Sugere-se a institucionalização da presente pesquisa a fim de estender o programa de verificação das instalações hidrossanitárias a outros edifícios da UFG, seja no mesmo Câmpus, ou até naqueles situados em outras cidades. Dessa forma, a Universidade pode formar um banco de dados que disponibilize informações importantes sobre serviços de manutenção, na tentativa de estabelecer as principais necessidades.

Propõe-se também, a formulação de pesquisas para estabelecer o perfil de consumo dos usuários das Faculdades de Farmácia e Odontologia. A partir disso, sugere-se o estabelecimento de ações para implantação de um PURA na edificação, que apresenta um dos maiores consumos de água da Universidade. Uma outra sugestão é o estudo da viabilidade da introdução de fontes alternativas de água, e com base nisso, a implantação de um PCA na edificação.

\section{REFERÊNCIAS}

CLARKE, R; KING, J. O Atlas da água. 1. ed. São Paulo: Publifolha, 2005.

GOMES, M. I. L. Implantação de um Programa de Uso Racional de Água na Universidade Federal de Goiás: Estudo de Caso Edifício da Reitoria. 2011. 93 f. Dissertação (Mestrado em Engenharia do Meio Ambiente) - Programa de Pós-Graduação Stricto Sensu em Engenharia do Meio Ambiente, Universidade Federal de Goiás, Goiânia, 2011.

MINISTÉRIO DAS CIDADES. Brasília. Programas Setoriais da Qualidade de Materiais (PSQs). PBQP-H - Brasileiro de Qualidade e Produtividade do Habitat. Disponível em: $<$ http://www.cidades.gov.br/pbqp-h/relacao_PSQs.htm>. Acesso em: 26 nov. 2013.

NUNES, S. S. Estudo da conservação de água em edifícios localizados no campus da Universidade Estadual de Campinas. 2000. 145 f. Dissertação (Mestrado) - Faculdade de Engenharia Civil da Universidade Estadual de Campinas, UNICAMP. Campinas, 2000.

OLIVEIRA, L. H. Metodologia para a implantação de programa de uso racional da água em edifícios. 1999. 344p. Tese (Doutorado) - Escola Politécnica, Universidade de São Paulo. São Paulo, 1999.

OLIVEIRA, M. A. Método de avaliação de necessidades e prioridades de reabilitação de edifícios de instituições federais de ensino superior. 2013. 233 f. Dissertação (Mestrado em Engenharia Civil) - Programa de Pós-Graduação em Geotecnia, Estruturas e Construção Civil, Universidade Federal de Goiás, Goiânia, 2013.

SAUTCÚCK, C. A. Formulação de diretrizes para implantação de programas de conservação de água em edificações. 2004. 331 f. Dissertação (Mestrado) - Escola Politécnica, Universidade de São Paulo. São Paulo, 2004.

SAUTCHUK, C.; FARINA, H.; HESPANHOL, I. et al. Conservação e Reuso da Água em Edificações. 2. ed. São Paulo, 2006. 151 p.

SILVA, G. S. Programas Permanentes de Uso Racional da Água em Campi Universitários: O Programa de Uso Racional da Água da Universidade de São Paulo. 2004. 328 f. 2v.

Dissertação (Mestrado) - Escola Politécnica, Universidade de São Paulo. São Paulo, 2004. 